\title{
Patient switching in a list patient system
}

Tor Iversen

Institute of Health Management and Health Economics,

University of Oslo

\section{Hilde Lurås}

Helse Sør-Øst Health Services Research Centre,

Akershus University Hospital

Working paper 2008: 4

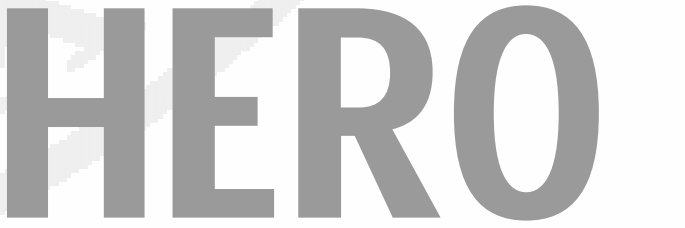




\title{
Patient switching in a list patient system
}

\author{
Tor Iversen \\ Institute of Health Management and Health Economics, University of Oslo \\ Hilde Lurås \\ Helse Sør-Øst Health Services Research Centre
}

\section{Health Economics Research Programme at the University of Oslo HERO 2008}

(C) 2008 HERO and the authors - Reproduction is permitted when the source is referred to. Health Economics Research Programme at the University of Oslo.

Financial support from The Research Council of Norway is acknowledged.

ISSN 1501-9071 (print version.), ISSN 1890-1735 (online), ISBN 82-7756-187-3 


\title{
Patient switching in a list patient system*
}

\author{
Tor Iversen \\ University of Oslo \\ Institute of Health Management and Health Economics \\ P.O. Box 1089 Blindern, NO-0317 Oslo, Norway \\ e-mail: tor.iversen@medisin.uio.no \\ Hilde Lurås \\ Helse Sør-Øst Health Services Research Centre \\ Akershus University Hospital \\ P.O. Box 95, NO-1478 Lørenskog, Norway \\ e-mail: hilde.luras@ahus.no
}

\begin{abstract}
We study whether the information patients have about physician quality when they choose a physician, influences their probability of switching physicians. We also study whether a physician with unfavorable characteristics, as perceived by patients (ex post), can compensate for patient switching by providing a higher quantity of services to his patients. If so, a trade-off exists between quality characteristics and quantity of services in the physician services market. From panel data covering the entire population of Norwegian general practitioners, we find that information on physician quality, as perceived by patients, has a huge effect on the volume of patients switching physicians. We also find that although physicians who experience patient shortages in general provide more services to their patients than physicians who have enough patients, the increased level of service provision only has a very small impact on the number of patients who decide to switch. We conclude that a higher level of service provision does not seem to compensate for negative characteristics (patients' impression of competence, empathy etc) of less popular physicians. We suggest that information about the volume of patient switching at the physician practice level should be made public.
\end{abstract}

JEL Classification: H42; I11; I18

Keywords: Switching; Economic motives; Capitation; General practice; Patient shortage

\footnotetext{
${ }^{*}$ Financial contribution from the Research Council of Norway is acknowledged. Iversen acknowledge financial contribution from the Research Council of Norway through the Health Economics Research Programme at the University of Oslo (HERO). Data is provided by Norwegian Social Science Data Service (NSD). NSD is neither responsible for data analyses nor interpretations. Thanks to participants at the Boston University / Harvard University /MIT Health Economics Seminar 5 April 2006, to participants at 6th European Conference on Health Economics, Budapest 6-9 July 2006, to discussant Mickael Bech and participants at the 27th Nordic Health Economists Study Group Meeting, Copenhagen 17-18 August 2006, to participants at the health economics seminar at the University of Oslo 12 September 2006, to discussant Erik Schokkaert and participants at the international workshop on health economics in Bergen 23-24 November 2006, to participants at the department seminar at the Department of Economics, University of Oslo 16 March 2007, to participants at the 6th World Congress of the International Health Economics Association, Copenhagen 8 -11 July 2007 and to Inger Cathrine Kann for helpful comments and suggestions to previous versions of this paper. The responsibility for all remaining errors is, of course, ours.
} 


\section{Introduction}

We study whether the information patients have about physician quality when they choose a physician, influences their probability of switching physicians. We also study whether a physician with unfavorable characteristics as perceived by patients (ex post) can compensate by providing a higher quantity of services to his or her patients. If so, a trade-off exists between quality characteristics and quantity of services in the physician services market.

This issue is related to Gravelle and Masiero (2000), who develop a theory of patients who switch physicians when they gain updated information about physician quality. They introduce two groups of patients: young and old. Young patients sign up with a general practitioner (GP) for the first time, and have imperfect information about quality. Old patients are already listed and know at the end of the first period the true quality of their GP, and hence, whether they underestimated or overestimated the quality when they were young. Old patients, however, are assumed to have no more information about other GPs than they had when they were young. Those who underestimated the quality of their GP, decide to stay with the physician. Those who overestimated their GP, decide to switch if the expected benefit exceeds the switching cost.

An implication of Gravelle and Masiero (2000) is that more information about physician quality when choosing a GP makes it less likely that patients switch physicians. We are able to test this implication empirically with data from the Norwegian regular general practitioner scheme (list patient system) introduced in 2001. The scheme implies that all residents are offered registration with a general practitioner and every general practitioner is given a list of patients to serve. Both among residents and general practitioners there is close to 100 percent participation in the new system. When the list patient system was established, physicians with enough patients got lists that consisted of patients who had this particular physician as their first choice. If the number of people who wanted to be listed with a GP exceeded the GP's preferred list size, priority was given to people who had been with the GP for a long time. These people were likely to be well informed about their GP's quality and hence, not likely to switch to another GP. Alternatively, for physicians with a shortage (deficit) of patients only 60 percent of the patients had their GP as the first choice. About 30 percent of the patients had not expressed preference for a physician and were assigned a physician administratively. 
These patients initially had less knowledge of their GP's quality. Hence, we have a positive relationship between patients' quality information and the proportion of patients on a GP's list who have this GP as their first choice, and a positive relationship between this proportion and the probability that the GP has enough patients. An implication is that GPs, who experience a patient shortage, are likely to have patients with less quality information. In Section 2 we construct a small model that elaborates on how patient shortage and quality information are related to the occurrence of patients switching physicians. The model also takes account of the possibility that the number of services a physician offers to his patients can have an impact on the number of switches he experiences.

The predictions from the model are compatible with Lurås (2007), who surveys a representative sample of Norwegians about whether or not they are satisfied with the GPs with whom they are listed. The responses to the survey are linked with some basic information about the physician with whom a person is listed. The survey reveals that being listed with a GP who experiences a shortage (deficit) of patients adds to the probability of being dissatisfied with the physicians' medical skills, interpersonal skills, referral practice and consultation length. But will dissatisfaction expressed by residents in a survey carry over to decisions about actually switching physicians? This is not obvious since in Hirschman's (1970) terms: while dissatisfaction is 'voice', switching is 'exit' and requires an alternative provider that is considered as better than the present one.

The literature on switching costs suggests that dissatisfaction may not result in actual switching. Klemperer (1995) summarizes some reasons. Of particular importance for our issue are:

- Transaction costs of switching suppliers: A person who considers switching must collect information about available physicians in his or her municipality and also do the administrative work related to the actual switching ${ }^{1}$.

- Costing of learning to use new brands: The present physician would have a lot of patient history information, while a new physician would need to acquire much of this information from the patient. Similarly, a relationship of mutual trust between physician and patient requires investments from both sides.

\footnotetext{
${ }^{1}$ The last item is now made easier for people with Internet connections. Since 2005 they can simply log into their personal page at the National Insurance Administration's Web page and make the switch online.
} 
- Psychological cost of switching or non-economic 'brand-loyalty: Some patients would perhaps feel that they will disappoint their present physicians if they switch.

- Uncertainty of the quality of untested brands: Physician services are experience goods in the sense that the quality for the individual patient is not actually revealed before an episode of illness occurs. This means that, even with extensive market search before making a switch, there is always uncertainty about the quality of an untested physician.

Hence, it is interesting to study empirically whether dissatisfaction, as expressed in surveys, in fact has consequences for actual switching.

In this study we have access to register data on patient switching, and we reveal patients' preferences by studying actual patient switching at the physician practice level. In addition to studying the effect of GP characteristics, we also explore to what extent physicians who experience a shortage of patients in fact manage to compensate for their less favorable characteristics by providing better accessibility and by offering more health care services to their patients. Physician behavior is elaborated on in Section 2, where a model that underlies the hypotheses to be tested, is presented. Section 3 presents data and some descriptive statistics. Empirical methods and results are presented in Section 4, while Section 5 concludes the paper. Our results show that both a small proportion of patients on the list having the GP as their first choice when the list patient system was introduced, and an experience of patient shortage (deficit) both result in more patient switching. Although physicians with a patient shortage in general provide more services to their patients compared with physicians who have enough patients, we find that the increased level of service provision only has a very small impact on the number of patients who decide to switch. We conclude that a higher level of service provision does not seem to compensate for characteristics of physicians that patients dislike.

\section{The model}

We suggest a small model of physician behavior and patients' switching behavior. Our approach stems from the observation of variation in practice style among physicians. For a number of encounters between a GP and his patient it is not clear what constitutes 'the right medical treatment'. An interesting consequence of the lack of medical standards is that 
several practice profiles are all regarded as satisfactory from a professional point of view. We assume that economic incentives have an effect on the intensity of service provision only in this area ${ }^{2}$.

There are two groups of patients: Group A, listed with their preferred GP and Group B, consisting of all other patients. The probability that a patient of group A switches GP is denoted $p_{A}$, and is for our purpose considered as exogenous. The probability that a patient of group B switches, is denoted as $p_{B}(k)$, and is assumed to depend on $k$, the number of health services being provided at the GP's discretion. Given a GP's exogenous characteristics, we assume that more services provided add to patients' satisfaction and hence, may lower the probability of patient switching among patients in group B: $p_{B}^{\prime}(k) \leq 0, p_{B}^{\prime \prime}(k) \geq 0, p(\infty)>0$. We also assume and $p_{A}<p_{B}$ for all values of $k$. For simplicity, we consider the flow demand for being added to a GP's list as an exogenous variable, denoted $z$ and equal across all GPs. Furthermore, $n_{i}(\mathrm{i}=\mathrm{A}, \mathrm{B})$ denotes the stock of patients listed such that $n_{A}+n_{B}=\mathrm{n}$. Eq. (1) expresses steady state, where the number of patients switching out of a list (i.e. $p_{A} n_{A}+p_{B}(k) n_{B}$ ) is equal to the number of patients added to the list, which is less than or equal to the flow demand for being added to the list $(z)$. Strict inequality means that some patients are rationed in the sense that their preference for being listed with a particular GP is not fulfilled:

$p_{A} n_{A}+p_{B}(k) n_{B} \leq z$

We assume that physicians maximize a quasi-linear utility function in monetary terms, $c+v(\ell)$, where $c$ is income (all income is consumed) and $\ell$ is leisure and that $v^{\prime}(\ell)>0$ and $v^{\prime \prime}(\ell)<0$. The net income from the physician's practice is defined as $q n+r n(\alpha+k)$, where $q$ is a capitation payment per person on the physician's list, $r$ is the fee per item of health service (or equivalently, a fee-for-service), and $n$ is the number of listed patients. The lowest acceptable level of service provision is denoted by $\alpha$. As an acceptable simplification for our purpose, we assume identical need for services among the physician's population of patients. The greater the need parameter is, the greater the minimum acceptable level of service provision. Health service provision above $\alpha, k$, is provided at the physician's discretion. The definition of leisure is $T-\operatorname{tn}(\alpha+k))$, where $T$ is the exogenous total time endowment and $t$ is an exogenously given time cost related to each service (consultation). The physician's

\footnotetext{
${ }^{2}$ Iversen and Lurås (2000) elaborate on this argument.
} 
practice profile is characterized by the length of the list and the number of services per listed person. The physician maximizes a constrained quasi-linear utility function:

$$
\begin{aligned}
& \underset{n, k}{\operatorname{Max}} q n+\operatorname{rn}(\alpha+k)+v[T-\operatorname{tn}(\alpha+k)] \\
& \text { s.t. } \\
& p_{A} n_{A}+p_{B}(k) n_{B} \leq z
\end{aligned}
$$

The constraint says that the number of patients should be maintained in the long run, i.e. steady state is assumed.

We can differentiate among three groups of GPs in steady state:

Type I: $p_{A} n_{A} \leq z$ :

This group consists of very popular GPs, in the sense that the entire list is made up of individuals having this particular GP as their first choice (i.e. $n_{A}>0, n_{B}=0$ ). Optimal number of patients and service provision for this group is found by maximizing (2) unconstrained:

$\operatorname{Max}_{n_{A}, k} q n_{A}+r n_{A}(\alpha+k)+v\left[T-t n_{A}(\alpha+k)\right]$

First order conditions for a maximum are:

$\left[r-v^{\prime}(\ell) t\right] n_{A} \leq 0$

$q+\left[r-v^{\prime}(\ell) t\right](\alpha+k)=0$

where the lhs of (4) is the GP's utility from an additional consultation and the lhs of (5) expresses his or her utility from an additional person listed. From (5) we see that $\left[r-v^{\prime}(\ell) t\right]<0$. The lhs of (4) is then negative, and accordingly $k=0$. This GP experiences an excess demand of people who prefer to be listed with him or her. Since the capitation fee is positive, it is always more rewarding for the GP to add new people to the list than to increase the level of service provision to those already listed ${ }^{3}$. Hence, $k=0$, and the minimum service intensity is offered.

Neither of the remaining two types of GPs achieve their optimal number of patients only from Group A. Hence, they have $n_{A} \geq 0$ and $n_{B}>0$.

\footnotetext{
${ }^{3}$ In Iversen and Lurås (2000) we show that this may not be true with more than one type of service, if relative fees deviate too much from relative costs of providing them.
} 
In steady state we then have:

$p_{A} n_{A}+p_{B}(k) n_{B}=z$

Eq. (6) determines $n_{B}$ as a function of $n_{A}, z$ and $k$ :

$n_{B}=n_{B}\left(n_{A}, z, k\right)$

where the signs below the function arguments denote the sign of the partial derivative. The optimal values of $k$ and $n_{B}$ in steady state are now found by maximizing:

$$
\begin{aligned}
& \underset{k}{\operatorname{Max}_{k}} q\left(n_{A}+n_{B}\right)+r\left(n_{A}+n_{B}\right)(\alpha+k)+v\left[T-t\left(n_{A}+n_{B}\right)(\alpha+k)\right] \\
& \text { s.t. } \\
& n_{B}=n_{B}\left(n_{A}, z, k\right)
\end{aligned}
$$

The first order condition for a maximum of (8) is:

$$
r n+[r(\alpha+k)+q] n_{B k}^{\prime}-v^{\prime}(\ell) t\left[n+(\alpha+k) n_{B k}^{\prime}\right] \leq 0
$$

where $n_{B k}^{\prime}$ is the partial derivative of $n_{B}$ with respect to $k$.

We can now distinguish between Type 2 and Type 3.

Type 2: $p_{A} n_{A}+p_{B}(0) n_{B}=z$ :

The first term in (9) measures the income from providing extra services to the people already listed. The second term measures the income from additional patients who are attracted to the list because of the increased level of services provision. The third term of (9) (after the minus sign) measures the loss in utility related to the increase in working time. This GP may be content with his number of patients, in which case (9) is fulfilled with equality for $k=0$. Alternatively, he may also have preferred more patients, higher income, and less leisure given that $k=0$. But since $k$ must be greater than zero to attract more patients, the income from providing more services is considered to be too small to compensate for the loss of leisure. Hence, the lhs of (9) is still equal to zero for $k=0$ but the GP now experiences a shortage of patients. This is typically expected to happen if the difference between the preferred and actual number of patients is small, if $q$ is small relative to the fee-for-service component, or if the impact of the service provision on additional patients listed is considered to be small. 
Type 3: High service intensity; $p_{A} n_{A}+p_{B}(k) n_{B}=z$ and $k>0$ :

A type 3 physician is characterized by marginal utility from income exceeding the marginal disutility from work at $\mathrm{k}=0$. Hence, (9) is fulfilled with equality for $k>0$.

We summarize the results with regard to the volume of switching:

Type 1 physicians have only patients who have this particular physician as their first choice, i.e. $\mathrm{n}_{\mathrm{A}}>0$ and $n_{B}=0$. In this case patients are rationed in the sense that not everyone who would have preferred to be listed with a Type $1 \mathrm{GP}$ is admitted. Type 2 and type 3 have in common that $\mathrm{n}_{\mathrm{A}} \geq 0$ and $n_{B}>0$. Since $p_{B}>p_{A}$, the number of patients switching out is higher in steady state for type 2 and type 3 than for type 1. Since the inflow of patients is considered exogenous and equal for both types, the flow of patients switching out is not expected to differ between type 2 and type 3. The amount of switching adjusted for the number of patients will however differ. The proportion of switching out of a list can in steady state be expressed as $\frac{z}{n_{A}+n_{B}}$. Since type 3 , because of more service intensive practice style, has a higher stock of patients compared with type 2, the denominator is higher for type 3 than for type 2. It follows that the flow of switching out adjusted for list size is predicted to be greater for type 2 than for type 3.

The following hypotheses emerge from the model and will be tested empirically:

- An increase in the proportion of a list having expressed the GP as the first choice, results in less switching out of the list

- A shortage of patients increases the number switching out of the list

- An increase in the level of service provision results in less switching out of the list for a GP who experiences a shortage of patients

\section{Data and descriptives}

This study exploits data from the Norwegian list patient system. Norway has a national health service financed by general taxation. For an average GP, 30 percent of the practice income is expected to come from the capitation fee, and the remaining 70 percent is split rather equally between co-payments from patients and fees from the insurance. Prior to the implementation 
of the list patient system in 2001, all Norwegian residents (4.5 million) were given the opportunity to complete and return a form to the National Insurance Administration (NIA), stating three preferred GPs in descending order. GPs, on the other hand, informed the NIA of their preferred number of patients. In the next step inhabitants and GPs were matched at the level of municipality according to an allocation algorithm made for the purpose. If the preferred number of patients stated by a GP was smaller than the number of residents who wanted to be listed with him or her, priority was given to former and current patients according to the stated number of years with the physician. After the first round of assignments, a considerable number of the GPs ended up with a smaller number of patients than they preferred. On the other hand, approximately 30 percent of the population had not expressed a preference for a particular GP. These people were assigned to the GPs who still had spare capacity, but even after the final round a considerable proportion of the GPs had not reached their preferred list size.

According to regulation, patients are allowed to switch GPs a maximum of twice a year. The switching is organized by the NIA, and a patient may switch by coming to a local branch of the NIA, by calling, or (from 2005 and onwards) by visiting the Internet page: https://is.trygdeetaten.no/rtv-minfastlege/innbygger/visloginside.do.

There may be several explanations for switching physicians. The database from NIA distinguishes between patient switching initiated by the physician because a GP has reduced or ended his practice, and patient switching initiated by the patient because the person has moved from the municipality, because of 'an ordinary switch' and because of 'other reasons'. Among the possible reasons listed in the NIA database for switching physicians, we conclude that patient dissatisfaction is best captured by "ordinary switch" and "other reasons." Because we are particularly interested in studying the number of switches due to patient dissatisfaction, we denote people who leave a list because of these reasons as the number of people who switch physicians. Annually about three percent of people on an average list switch physicians because of these reasons. This is more than the 1.5 percent that is reported in England by Dixon et al. (1997), and the 1 percent reported in Denmark by Bjerrum et al. (1992). 


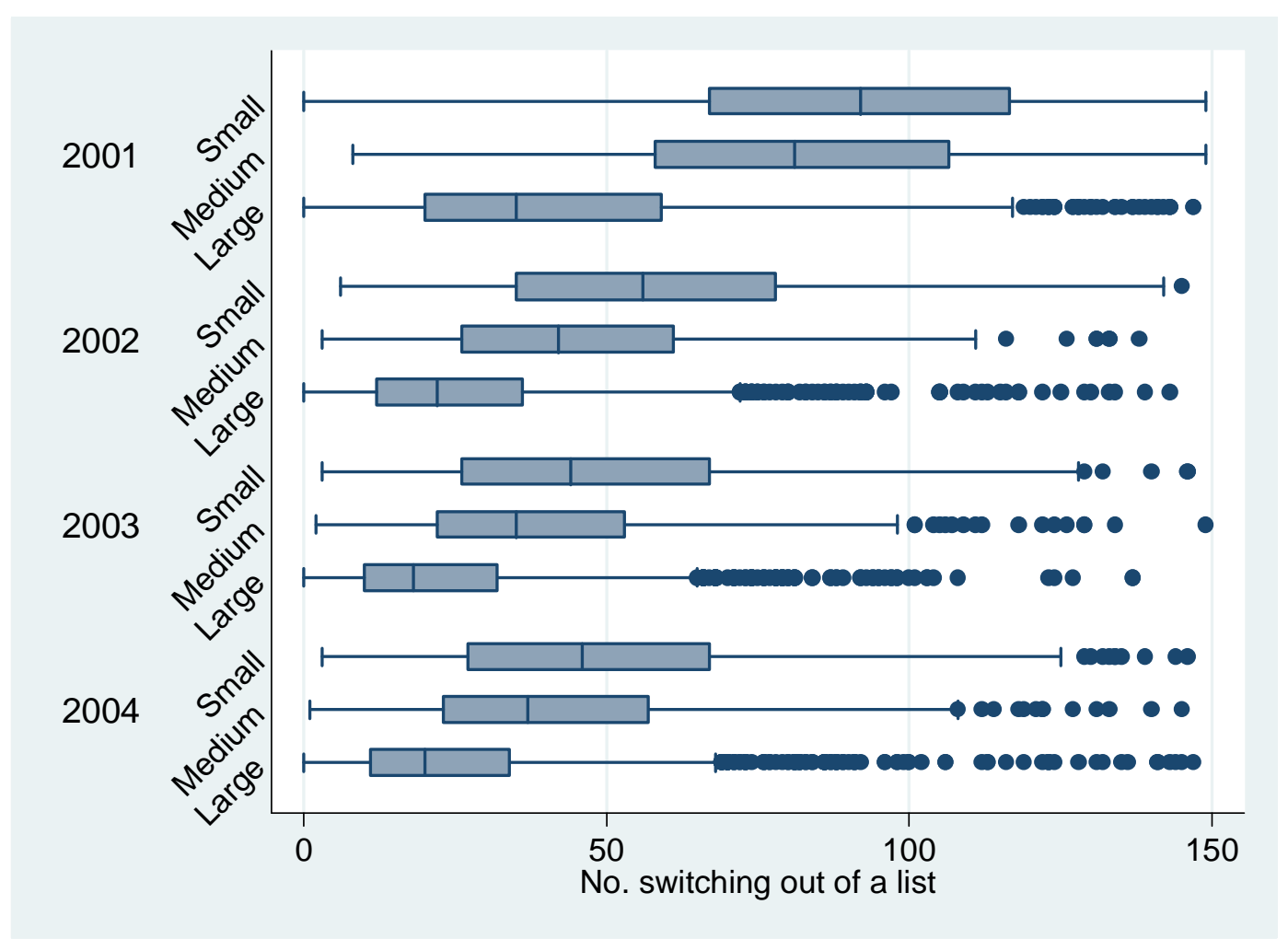

Figure 1 No. switching out the list according to year and proportion of the list who have the GP as their first choice $($ No. observations $=10,239)$

Figure 1 shows a boxplot ${ }^{4}$ of the number of patients switching physicians according to year, and the proportion of the list who had the GP as their first choice when the system was introduced. The term Small refers to GPs with 50 percent or less of the list consisting of patients who have the GP as their first choice. The term Medium refers to a proportion between 50 percent and 75 percent, and Large means more that 75 percent $^{5}$. We see from Figure 1 that the distribution of switching is according to the predictions from the theoretical model: A Large proportion of patients who have preferred to be listed with a GP is mirrored in a smaller mean number of switches (shown by the vertical line inside the boxes) in all periods.

\footnotetext{
${ }^{4}$ Observations in the box are between the 25 th percentile and the 75 th percentile

${ }^{5}$ The composition of GPs is 18 percent Small, 18 percent Medium and 64 percent Large.
} 


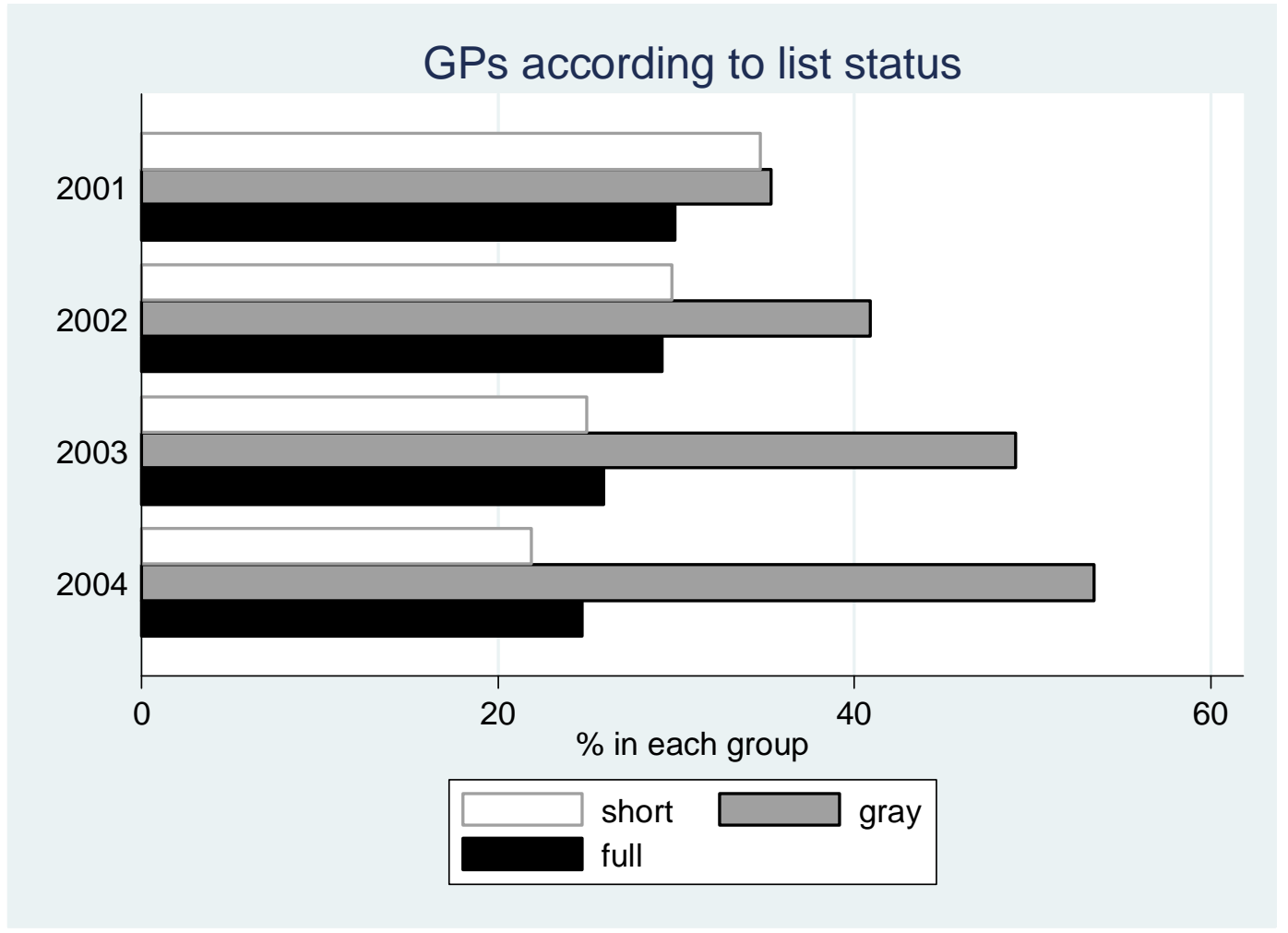

Figure 2 GPs according to list status $($ No. GPs $=2570)$

Figure 2 shows the distribution of GPs according to list status and year ${ }^{6}$. GPs are divided into three groups: Those with a discrepancy of at least 100 between preferred and actual list size are said to experience a shortage of patients and are denominated as Short. Those with a discrepancy between preferred and actual list between zero and 100 patients represent a gray area in the sense that we do not really know whether they consider the discrepancy to be costly to them. According to local health authorities some GPs should have open lists to offer new residents a choice of GP and also to offer an alternative option for those residents who are dissatisfied with their present GPs. Some GPs may then have open lists because they feel obliged to contribute to an actual choice for the population. That means they are probably rather indifferent between having the current list and having some additional patients. This group of physicians is denominated as Gray in Figure 2. The third group, denominated Full,

\footnotetext{
${ }^{6}$ A total number of 3650 GPs contracted with the regular general practitioner scheme when the system was introduced. We exclude from the analysis those GPs who ended the contract since system was introduced and the approximately ten per cent of the GPs who are public employees. We also exclude 155 GPs who participated in a trial that preceded the nationwide regular general practitioner scheme. This leaves us with a panel of 2570 GPs.
} 
consists of those GPs with actual lists equal to or greater than their preferred lists ${ }^{7}$. From Figure 2 we see that the percentage of GPs who experience a shortage of patients steadily declines from 33 percent in 2001 to 21 percent in 2004. Also, the proportion with full lists declines somewhat, from 30 percent in 2001 to 26 percent in 2004. These declines are balanced by an increase in the proportion of GPs in the gray area from 37 percent to 54 percent during the period. A more detailed description of transitions between states shows that 22 percent of the GPs who were Short in the previous period are Gray or Full in this period, while only three percent of those who were Gray or Full in the previous period end up as Short in this period. Hence, transitions between states are not symmetric.

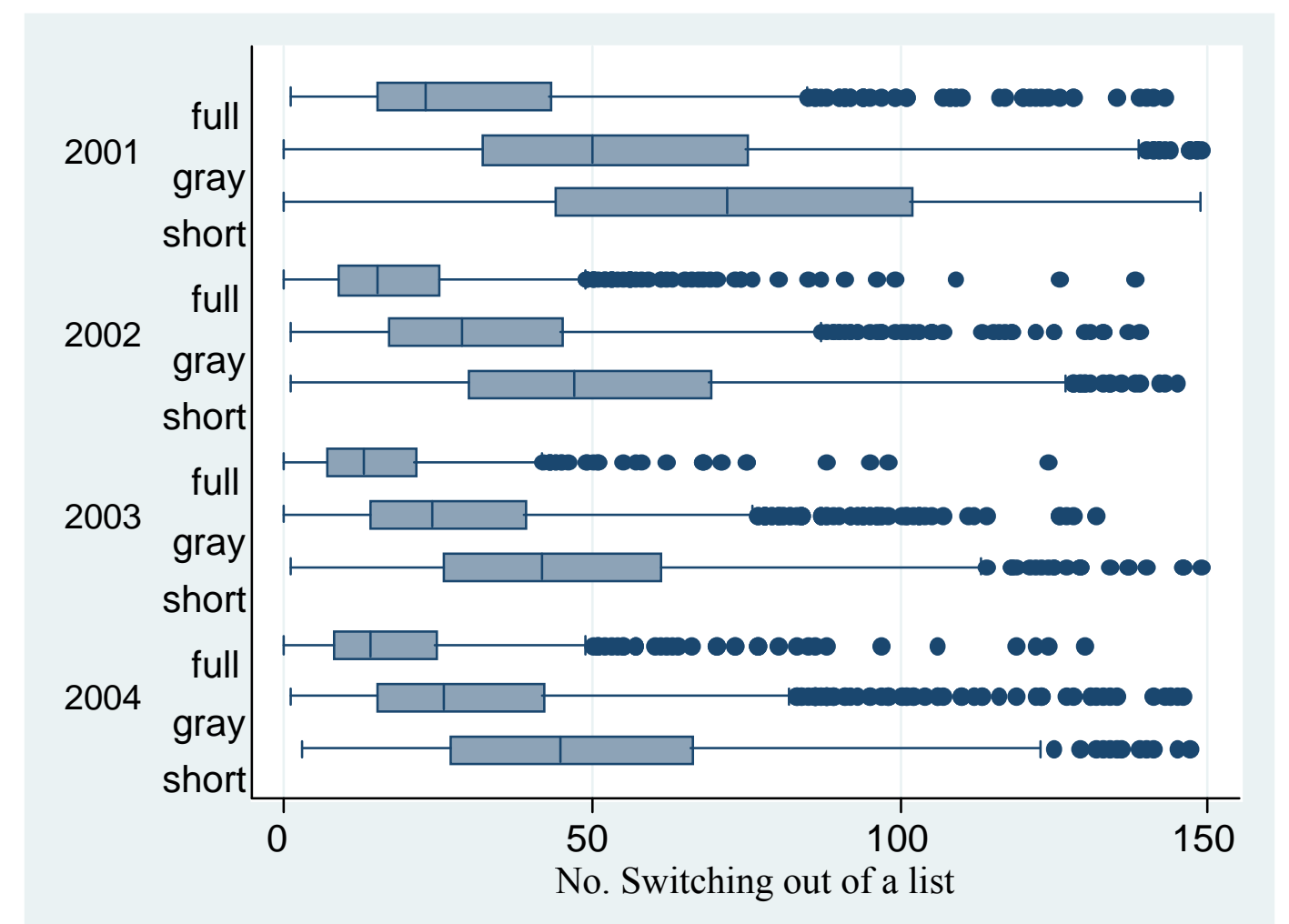

Figure 3 No. switching out of a list according to year and GP's list status (No. observations $=10,261$ )

Figure 3 shows a box plot of the annual number of people who switch physician according to year and a GP's list status. We see that the mean number of people who leave a list (shown by the vertical line inside the boxes) is greater for Short than for Gray and greater for Gray than

\footnotetext{
${ }^{7}$ Only 5-6 percent of the physicians have a list that is greater than their preferred.
} 
for Full in all years. We also see that after 2001 for each of the three subgroups the mean number of people who switch is quite stable from one year to the next. In 2004, an average of 21 people switched from the list of a Full GP, on average 35 from a Gray GP, and on average 55 from a Short GP. We have also plotted the mean number of people who are added to the lists according to year and list status of the GPs (Figure A1 in the appendix). We find that the mean numbers are rather stable after 2001 within each group, and that relative additions according to groups are similar to the relative switches, as described in Figure 3. Hence, a tendency towards steady-state is suggested ${ }^{8}$.

Table 1 shows descriptive statistics for the panel as a whole, while Table 2 shows the descriptives according to the GPs' list status: Full, Gray, or Short. The last two columns of Table 1 decompose the standard deviation into the variation between the average of observations of GPs (between) and the variation over time (within) for the individual GP. Variables are grouped according to variables that characterize the patient list, variables that characterize the GP's practice profile, variables that characterize the GP and finally, variables that characterize the municipality a GP practices in.

The mean size of a list is 1,270 people. We see that the between variation accounts for 85 percent of the total variation. From Table 2 we see that the mean list size for the three groups differs with a magnitude of about 100 patients, with Full having the longest lists. Proplist is a time-independent variable that shows the number of persons having a particular GP as their first choice when the list system was established relative to the size of a GP's patient list. Table 1 shows that for GPs as a whole this proportion is 80 , but from Table 2 we see that the proportion varies considerably between the three groups. While Full was the first choice for the entire list of patients, only 61 percent of the patients on a Short list had their GP as first choice.

We see from Table 1 that on average 12 percent of the patients on a list are 70 years or older and 51 percent are females. We also see that 90 percent of the variation in the composition of the list according to age and gender is due to variation between physicians. From Table 2 we see that the three groups are quite similar with regard to the proportion of elderly listed, while there are differences regarding the proportion of females, with Full having the greatest

\footnotetext{
${ }^{8}$ As explained previously, Figures 1 and 3 only describe the numbers who switch physician because of assumed dissatisfaction with the physician.
} 
Table 1 Descriptive statistics for the panel

\begin{tabular}{|c|c|c|c|c|c|c|c|}
\hline Variable & Definition & mean & std. & $\min$ & $\max$ & $\mathrm{b}$ & $\mathrm{W}$ \\
\hline \multicolumn{8}{|l|}{ The list } \\
\hline Switch & $\begin{array}{l}\text { Annual no. switching (\# obs } \\
=10239 \text { ) }\end{array}$ & 43.1 & 43.8 & 0 & 956 & 0.54 & 0.46 \\
\hline List & $\begin{array}{l}\text { The size of the list in terms of } \\
1000 \text { people listed (\#obs } \\
=10171 \text { ) }\end{array}$ & 1.270 & 0.380 & 0.121 & 2.832 & 0.85 & 0.15 \\
\hline Proplist & $\begin{array}{l}\text { The number of people having } \\
\text { the GP as their first choice as a } \\
\text { proportion of the GP's list } \\
\text { January } 1^{\text {st }} 2002 \text { (\#obs=2326) }\end{array}$ & 0.85 & 0.35 & 0.003 & 3.2 & 1 & 0 \\
\hline Propold & $\begin{array}{l}\text { The proportion of persons aged } \\
70 \text { and older on the list }(\# \text { obs }= \\
9978)\end{array}$ & 0.12 & 0.06 & 0 & 0.42 & 0.90 & 0.10 \\
\hline Propfem & $\begin{array}{l}\text { The proportion of females on the } \\
\text { list }(\# \text { obs }=10117)\end{array}$ & 0.51 & 0.10 & 0.15 & 0.91 & 0.90 & 0.10 \\
\hline \multicolumn{8}{|c|}{ The practice profile } \\
\hline Feepercap & $\begin{array}{l}\text { Mean annual income in NOK } \\
\text { from fees paid by insurance per } \\
\text { listed person (\# obs }(2002-2004) \\
=7597)\end{array}$ & 434.0 & 207.9 & 0 & 4378.0 & 0.71 & 0.29 \\
\hline Consult & $\begin{array}{l}\text { Mean no. of consultations per } \\
1000 \text { listed during one month (\# } \\
\text { obs }=4209 \text { ) }\end{array}$ & 214.4 & 84.7 & 0.6 & 1102 & 0.66 & 0.34 \\
\hline Duration & $\begin{array}{l}\text { Mean no. of consultations per } \\
1,000 \text { listed where duration } \\
\text { dependent fee is used during one } \\
\text { month }(\# \text { obs }=4191 \text { ) }\end{array}$ & 63.0 & 47.0 & 0.6 & 612.4 & 0.73 & 0.27 \\
\hline \multicolumn{8}{|c|}{ (2) } \\
\hline Male & $\begin{array}{l}\text { A dummy variable equal to one } \\
\text { if the physician is a male (\# obs } \\
=2570 \text { ) }\end{array}$ & 0.73 & & 0 & 1 & 1 & 0 \\
\hline Age & $\begin{array}{l}\text { The GP's age in years in } 2001 \text { (\# } \\
\text { obs }=2570)\end{array}$ & 46.7 & 8.05 & 26 & 71 & 1 & 0 \\
\hline Specialist1 & $\begin{array}{l}\text { A dummy variable equal to one } \\
\text { if the physician is a specialist in } \\
\text { general medicine in } 2001 \text { (\# obs } \\
=2570 \text { ) }\end{array}$ & 0.58 & & 0 & 1 & 1 & 0 \\
\hline Specialist2 & $\begin{array}{l}\text { A dummy variable equal to one } \\
\text { if the physician is a specialist in } \\
\text { community in } 2001 \text { medicine } \\
\text { (\#obs }=2570 \text { ) }\end{array}$ & 0.08 & & 0 & 1 & 1 & 0 \\
\hline $\begin{array}{l}\text { Norwegian } \\
\text { The munici }\end{array}$ & The GP is Norwegian citizen & 0.91 & & 0 & 1 & 1 & 0 \\
\hline Capacity & $\begin{array}{l}\text { \# GPs who accept new patients } \\
\text { (\#obs }=10182\end{array}$ & 61.3 & 111.7 & 0 & 341 & 0.94 & 0.06 \\
\hline Population & $\begin{array}{l}\text { Residents of the municipality in } \\
1000(\# \text { obs }=10280)\end{array}$ & 111.2 & 175.2 & 0.7 & 529.9 & 0.99 & 0.01 \\
\hline
\end{tabular}

$\mathrm{b}(\mathrm{w})$ is between (within) physician variation as a proportion of total variation 
Table 2 Descriptive statistics according to physicians' list status

\begin{tabular}{|c|c|c|c|c|c|c|c|}
\hline \multirow[t]{2}{*}{ Variable } & \multirow[t]{2}{*}{ Definition } & \multicolumn{2}{|c|}{$\begin{array}{c}\text { Full }=1 \\
\text { (preferred }- \\
\text { actual } \leq 0 \text { ) }\end{array}$} & \multicolumn{2}{|c|}{$\begin{array}{c}\text { Gray }=1 \\
(0<\text { preferred- } \\
\text { actual } \leq 100)\end{array}$} & \multicolumn{2}{|c|}{$\begin{array}{c}\text { Short }=1 \\
\text { (preferred - } \\
\text { actual }>100\end{array}$} \\
\hline & & Mean & Std & Mean & Std & Mean & Std \\
\hline \multicolumn{8}{|l|}{ The list } \\
\hline Switch & $\begin{array}{l}\text { Annual no. switching (\# obs } \\
=10239 \text { ) }\end{array}$ & 23.3 & 24.6 & 38.8 & 33.0 & 69.8 & 58.7 \\
\hline List & $\begin{array}{l}\text { The size of the list in terms of } \\
1000 \text { people listed (\# obs } \\
=10171 \text { ) }\end{array}$ & 1.367 & 0.376 & 1.270 & 0.377 & 1.172 & 0.365 \\
\hline Proplist & $\begin{array}{l}\text { The number of people having } \\
\text { the GP as their first choice as a } \\
\text { proportion of the GP's list } \\
\text { January } 1^{\text {st }} 2002(\# \text { obs }=2326)\end{array}$ & 1.08 & 0.34 & 0.82 & 0.29 & 0.61 & 0.27 \\
\hline Propold & $\begin{array}{l}\text { The proportion of persons } \\
\text { aged } 70 \text { and older on the list (\# } \\
\text { obs }=9978 \text { ) }\end{array}$ & 0.12 & 0.06 & 0.12 & 0.06 & 0.12 & 0.06 \\
\hline Propfem & $\begin{array}{l}\text { The proportion of females on } \\
\text { the list }(\# \text { obs }=10117)\end{array}$ & 0.55 & 0.11 & 0.51 & 0.09 & 0.47 & 0.08 \\
\hline \multicolumn{8}{|c|}{ The practice profile } \\
\hline Feepercap & $\begin{array}{l}\text { Mean annual income in NOK } \\
\text { from fees paid by insurance } \\
\text { per listed person (\# obs }= \\
7597 \text { ) }\end{array}$ & 435.4 & 169.9 & 420.9 & 188.3 & 457.3 & 269.7 \\
\hline Consult & $\begin{array}{l}\text { Mean no. of consultations per } \\
1000 \text { listed during one month } \\
(\# \text { obs }=4209)\end{array}$ & 209.6 & 72.7 & 211.5 & 81.9 & 224.6 & 99.2 \\
\hline Duration & $\begin{array}{l}\text { Mean no. of consultations per } \\
1,000 \text { listed where duration } \\
\text { dependent fee is used during } \\
\text { one month (\# obs }=4191 \text { ) }\end{array}$ & 58.4 & 43.3 & 62.0 & 43.2 & 69.8 & 55.9 \\
\hline \multicolumn{8}{|l|}{ The GP } \\
\hline Male & $\begin{array}{l}\text { A dummy variable equal to } \\
\text { one if the physician is a male } \\
\text { (\# obs }=2570)\end{array}$ & 0.66 & & 0.70 & & 0.84 & \\
\hline Age & $\begin{array}{l}\text { The GP's age in years (\# obs } \\
=10900 \text { ) }\end{array}$ & 47.1 & 7.0 & 46.3 & 8.3 & 46.8 & 8.6 \\
\hline Specialist1 & $\begin{array}{l}\text { A dummy variable equal to } \\
\text { one if the physician is a } \\
\text { specialist in general medicine } \\
(\# \text { obs }=2570 \text { ) }\end{array}$ & 0.68 & & 0.56 & & 0.50 & \\
\hline Specialist2 & $\begin{array}{l}\text { A dummy variable equal to } \\
\text { one if the physician is a } \\
\text { specialist in community } \\
\text { medicine }(\# \text { obs }=2570)\end{array}$ & 0.07 & & 0.09 & & 0.08 & \\
\hline Norwegian & The GP is Norwegian citizen & 0.94 & & 0.92 & & 0.85 & \\
\hline \multicolumn{8}{|c|}{ The municipality } \\
\hline Capacity & $\begin{array}{l}\text { No. of GPs in the municipality } \\
\text { who accept new patients (\# } \\
\text { obs }=10182 \text { ) }\end{array}$ & 30.3 & 73.7 & 58.6 & 110.4 & 95.6 & 132.8 \\
\hline Population & $\begin{array}{l}\text { Population of the municipality } \\
\text { in } 1000(\# \text { obs }=10280)\end{array}$ & 67 & 119 & 109 & 175 & 159 & 207 \\
\hline
\end{tabular}


proportion. Because we know that females prefer to be listed with female physicians this is probably related to the fact that, while female GPs account for 33 percent of Full, they only account for 17 percent of Short.

Feepercap shows the mean annual income in $\mathrm{NOK}^{9}$ from National Insurance per listed person $^{10}$. The figures are adjusted for annual changes in fee level by simply using the development of the consultation fee as a deflator. Figures are from 2002-2004. The year of 2001 is disregarded, since the system was only in operation for about half of that year. For the whole panel the mean income per listed person per year from fees paid by insurance is NOK 434. In addition to this sum, the GP receives an annual capitation fee (NOK 300 in 2004) and income from patient co-payment (NOK 117 per consultation in 2004). Table 2 shows a distinct difference in Feepercap between the three groups of GPs, with Short having the highest income per listed person. This is in accordance with our prediction from theory in Section 2, and is also supported empirically in Iversen (2005). According to the fee schedule, a GP receives an additional fee for every 15 minutes a consultation lasts beyond the first 20 minutes. For a GP with a shortage of patients, there are incentives for providing both more and longer consultations, compared with a GP with enough patients. From Table 2 we see that the mean number of (long) consultations per person listed in fact is higher for short than for full. This result is also supported by more thorough analysis reported in Iversen (2005).

After having fulfilled a particular post-graduate education program, a physician becomes a specialist in general medicine. Hence, being a specialist in general medicine may be considered a quality indicator attached to a GP. From Table 1 we see that 58 percent of the GPs are specialists in general medicine and from Table 2 we see a considerable difference between the subgroups of GPs with 68 percent of Full being specialists, while only 50 percent of Short have a similar specialization.

Capacity shows the number of GPs in a particular municipality who will accept new patients, i.e. the number of GPs that are available. On average, a GP is surrounded by 61.3 GPs with open lists in his or her municipality. We see from Table 2 that this figure varies greatly

\footnotetext{
${ }^{9}$ One USD is about NOK 5.00 .

${ }^{10}$ Compared to the claims data from NIA all service provision figures are reduced by 5 percent for full and gray and by 10 percent for short, since surveys of Norwegian GPs (see Grytten \& Sørensen, 2008) show that a proportion of the total services is provided to patients not listed and these external consultations occur more frequently if a GP experiences a shortage of patients.
} 
depending on the list status of the physician. While a GP in the subgroup Full on average has 30.3 GPs with open lists in his or her municipality, a GP in the subgroup Short has 94.6 GPs with open lists in his or her municipality. These figures mirror both variation in capacity at the municipal level and variation among municipalities regarding the number of inhabitants. In a municipality with high physician density, we would expect to find many open lists because of the large number of physicians. Hence, Capacity can be interpreted as an indicator of competition among GPs in the municipality. We predict that an increase in Capacity has a positive impact on the number of switches.

\section{Estimation and results}

For econometric analysis the Norwegian list patient system has several advantages:

1. There is close to 100 percent participation in the system, both among residents and among GPs. Hence, we need not pay attention to possible self-selection into the system.

2. Each GP's population of patients is known. Hence, we know whether a great number of services provided reflects many patients in the practice or the provision of many services to each patient.

3. Fees (including the magnitude of co-payments) are negotiated between the state and the Norwegian Medical Association. Hence, fees are fixed for the individual GP and the micro level market conditions have no effect on price.

We want to estimate factors that have an impact on Switch. Since we have panel data (four periods: 2001, 2002, 2003, and 2004), unobserved heterogeneity is likely to occur. Unobserved heterogeneity violates the assumptions of ordinary least squares regression, since error terms of different periods are likely to be correlated for each GP. We fit a standard model of the form ${ }^{11}$ :

$y_{i t}=\alpha_{i}+\mathbf{x}_{i t}^{\prime} \boldsymbol{\beta}+\mathbf{z}_{i}^{\prime} \gamma+\varepsilon_{i t} \quad(i=1, \ldots ., m ; \quad t=1, \ldots ., T)$

where $y_{i t}$ is the dependent variable with a subscript indicating observation number $t$ of GP number $i, \mathbf{x}_{i t}$ is a vector of time varying explanatory variables with a similar subscript, $\mathbf{z}_{\mathrm{i}}$ is a vector of time invariant variables, $\beta$ and $\gamma$ are vectors of coefficients to be estimated, and $\alpha_{i}+$

\footnotetext{
${ }^{11}$ See for instance Cameron and Trivedi (2005), Ch. 21.
} 
$\varepsilon_{i t}$ is the stochastic error term. The stochastic variable $\alpha_{i}$ is the GP specific random variable that captures unobserved heterogeneity and differs among GPs, but not for a particular GP over time. We assume that:

(a) $\mathrm{E}\left(\varepsilon_{\mathrm{it}}\right)=0$,

(b) $\operatorname{Var}\left(\varepsilon_{\mathrm{it}}\right)=\sigma_{\varepsilon}^{2}$

(c) $\operatorname{Cov}\left(\varepsilon_{\mathrm{it}}, \varepsilon_{\mathrm{is}}\right)=0$

(d) $E\left(\alpha_{i}\right)=0$

(e) $\operatorname{Var}\left(\alpha_{i}\right)=\sigma_{\alpha}^{2}$

(f) $\operatorname{Cov}\left(\alpha_{i}, \varepsilon_{\mathrm{it}}\right)=0$

For the random effects model to be valid, we should also have $\operatorname{Cov}\left(\alpha_{i}, x_{i, t}\right)=\operatorname{Cov}\left(\alpha_{i}, z_{i}\right)=0$. We test this restriction by means of a standard Hausman-test. If the restriction is rejected, the fixed effects model is selected. In the fixed-effects model $\alpha_{i}$ cancels, and, hence, the model is robust. If the random effects model is valid, the random effects estimators are, however, more efficient than the fixed effects estimators. In addition, we are also able to test the effect of time-invariant variables. Since the number who Switch to another list is positively skewed, we use the natural logarithm of Switch in the regressions. We also enter the natural logarithm of all continuous right hand side variables.

The independent variables that are included in the regressions correspond to the variables that were predicted to have an impact on Switch in the theoretical model. These variables are Proplist, predicted to have a negative impact on Switch; Short, predicted to have a positive impact on Switch; and the interaction term Feepercap*Short, predicted to have a negative impact on Switch ${ }^{12}$. As control variables we introduce variables that account for variation in the composition of the patient list (Propold and Propfem), variation in physician characteristics (Male, Mid-age, Old-age ${ }^{13}$, Norwegian, Specialist1 and Specialist2) and variation in accessibility and competition at the municipal level (Capacity).

\footnotetext{
${ }^{12}$ In supplementary analyses we used Consult and Duration as indicators of service provision. None of these displayed statistically significant effects and we omit them from further presentation.

${ }^{13}$ Age is converted to three dummy variables: Young-age equals 1 if Age $<35$ and 0 otherwise; Medium-age equals 1 if $35 \leq A g e<50$ and 0 otherwise; Old-age equals 1 if Age $\geq 50$ and 0 otherwise. Young-age is the reference group in the regressions.
} 
Table 3. The estimated effect (robust std) of practice characteristics and market conditions on the number of patients who SWITCH from a GP's list

\begin{tabular}{|c|c|c|c|c|}
\hline & $\begin{array}{l}\text { Ln Switch } \\
\text { Fixed effects } \\
\text { estimation }\end{array}$ & $\begin{array}{l}\text { Ln Switch } \\
\text { Random effects } \\
\text { estimation }\end{array}$ & \multicolumn{2}{|c|}{$\begin{array}{c}\text { Ln Switch } \\
\text { Hausman-Taylor } \\
\text { estimation }\end{array}$} \\
\hline Short & $0.52^{* *}(0.08)$ & $0.80^{* *}(0.08)$ & TVen & $0.51^{* *}(0.08)$ \\
\hline Gray & $0.09^{* *}(0.02)$ & $0.23^{* *}(0.02)$ & TVen & $0.09^{* *}(0.02)$ \\
\hline Many & $-0.02(0.04)$ & $-0.10^{* *}(0.03)$ & TVen & $-0.02(0.03)$ \\
\hline Proplist & & $-0.52^{* *}(0.02)$ & TIen & $-1.14^{* *}(0.23)$ \\
\hline Proplist *Short & $-0.20^{* *}(0.03)$ & $-0.02(0.03)$ & TVen & $-0.20^{* *}(0.03)$ \\
\hline Feepercap*Short & $-0.09^{* *}(0.01)$ & $-0.07^{* *}(0.01)$ & TVex & $-0.08^{* *}(0.01)$ \\
\hline List & $1.39^{* *}(0.10)$ & $0.82^{* *}(0.03)$ & TVex & $1.28^{* *}(0.08)$ \\
\hline Propold & $0.07(0.06)$ & $-0.002(0.02)$ & TVex & $0.09(0.04)$ \\
\hline Propfem & $-0.55^{*}(0.21)$ & $-0.79^{* *}(0.08)$ & TVex & $-0.37^{*}(0.17)$ \\
\hline Man & & $-0.26^{* *}(0.03)$ & TIex & $-0.24^{*}(0.12)$ \\
\hline Mid-age & & $0.11^{*}(0.04)$ & TIex & $0.64(0.43)$ \\
\hline Old-age & & $0.26^{* *}(0.05)$ & TIex & $0.86^{*}(0.43)$ \\
\hline Norwegian & & $-0.18^{* *}(0.04)$ & TIex & $-0.09(0.14)$ \\
\hline Specialist1 & & $-0.11^{* *}(0.02)$ & TIen & $-0.38(0.91)$ \\
\hline Specialist2 & & $0.02(0.04)$ & TIex & $0.15(0.27)$ \\
\hline Capacity & $0.18^{* *}(0.02)$ & $0.13^{* * *}(0.006)$ & TVex & $0.15^{* *}(0.01)$ \\
\hline Medlcent & & $0.18^{* *}(0.05)$ & TIex & $0.13(0.16)$ \\
\hline Med2cent & & $0.32^{* *}(0.04)$ & TIex & $0.16(0.17)$ \\
\hline Highcent & & $0.31^{* *}(0.04)$ & TIex & $0.15(0.15)$ \\
\hline Constant & & $-3.87^{* *}(0.24)$ & & $-7.30^{* *}(0.62)$ \\
\hline $\begin{array}{l}\text { Dummies for } \\
\text { years }\end{array}$ & Yes & Yes & & Yes \\
\hline Adjusted $R^{2}$ & 0.30 & & & \\
\hline $\begin{array}{l}\text { Number of } \\
\text { observations }\end{array}$ & 8866 & 8866 & & 8866 \\
\hline No. GPs & 2321 & 2321 & & 2321 \\
\hline $\begin{array}{l}\text { No. observations } \\
\text { per GP }\end{array}$ & $\begin{array}{l}\text { Min: } 1 \\
\text { Avg: } 3.8 \\
\text { Max: } 4\end{array}$ & $\begin{array}{l}\text { Min: } 1 \\
\text { Avg: } 3.8 \\
\text { Max: } 4\end{array}$ & & $\begin{array}{l}\text { Min: } 1 \\
\text { Avg: } 3.8 \\
\text { Max: } 4\end{array}$ \\
\hline $\begin{array}{l}\text { Hausman } \\
\text { test }\end{array}$ & & $\begin{array}{l}\text { CHISQ }(12)= \\
774.23 \\
\text { p-value }=0.000\end{array}$ & $\begin{array}{l}\text { CHISQ( } \\
\text { p-value }\end{array}$ & $\begin{array}{l}\text { 12) }=6.90 \\
=0.8643\end{array}$ \\
\hline
\end{tabular}

${ }^{*} \cdot\left({ }^{* * *}\right)$ indicates that the estimated parameter is significantly different from zero at the five (one) percent level with a two tailed test.

TVex denotes time varying exogenous variable TVen denotes time varying endogenous variable TIex denotes time invariant exogenous variable TIen denotes time invariant endogenous variable 


\section{Fixed effects estimation}

Table 3 shows the results from the regression analyses. As shown in the bottom line of the table, the Hausman test rejects the random effects model. The results of the fixed effects estimation show a statistically significant effect with the expected sign of Short on Switch. The magnitude of the estimated effect is 0.52 , meaning that occurrence of patient shortage (Short) is estimated to increase the number of switches (Switch) from a GP's list by 52 percent. From the interaction term Proplist*Short we see that a high proportion of patients having the GP as first choice contributes to a decline in switches (Switch) for GPs with a shortage of patients. The estimated coefficient of Feepercap*Short shows the effect on switching (Switch) of an increase in the level of service provision for GPs who experience patient shortage. The effect is statistically significant and has the expected sign. But the magnitude of the effect is very small. An elasticity of - 0.09 means that a one per cent increase in service provision (Feepercap) is expected to decrease the magnitude of switching (Switch) by 0.09 percent. Hence, if GPs experiencing patient shortage increase the sum of fees per person by NOK 100 (22 percent increase from the mean for Short), the number of switches is predicted to decline by 2 percent or between one and two persons per year per list (calculated from mean of Switch from group Short). Hence, an increase in the intensity of service provision does not seem to have an effect of any practical interest to the physician. We have also done the regressions with lagged values of service provision without having any change in results.

The proportion of females on a list (Propfem) contributes to a lower number of switches (Switch). This may reflect females, in general, being more loyal patients. Another hypothesis might be more plausible: Females often have a preference for a female GP. Since female GPs are a minority, female patients have fewer options available. We also see that the number of physicians in the municipality who accept new patients (Capacity) has a positive impact on the number of patients who switch, as predicted. The magnitude of the effect is not very great. If the number of GPs with open lists increases by 10 percent from the mean (61.3), the number of switches (Switch) is estimated to increase by 1.8 percent or between one and two persons per list per year.

\section{Hausman- Taylor estimation}

Since the fixed effects method only makes use of the within variation of each GP, the effect of the time invariant variables is not estimated. Hence, the effect of a core variable in the study, 
Proplist, is included in the fixed effect and cannot be estimated separately. To overcome this problem Hausman and Taylor (1981) suggest an instrumental variable approach. We start out (Green, 2003, p. 303) by splitting the vectors of explanatory variables in (10) into:

$y_{i t}=\alpha_{i}+\mathbf{x}_{1 i t}^{\prime} \boldsymbol{\beta}_{1}+\mathbf{x}_{2 i t}^{\prime} \boldsymbol{\beta}_{2}+\mathbf{z}_{1 i}^{\prime} \gamma_{1}+\mathbf{z}_{2 \mathbf{i}}^{\prime} \gamma_{2}+\varepsilon_{i, t} \quad(i=1, \ldots ., m ; \quad t=1, \ldots ., T)$

where

$\mathbf{x}_{1 \text { it }}$ is $K_{1}$ variables that are time varying and uncorrelated with $\alpha_{i}$

$\mathbf{z}_{1 \text { it }}$ is $L_{1}$ variables that are time invariant and uncorrelated with $\alpha_{i}$

$\mathbf{x}_{2 \text { it }}$ is $K_{2}$ variables that are time varying and correlated with $\alpha_{i}$

$\mathbf{z}_{2 i t}$ is $L_{2}$ variables that are time invariant and correlated with $\alpha_{i}$

The method contains the following steps. In step $1 \boldsymbol{\beta}_{\mathbf{1}}$ and $\boldsymbol{\beta}_{2}$ are estimated by fixed effects estimation. The residual variance estimator from this regression is a consistent estimator of $\sigma_{\varepsilon}^{2}$. In step 2 the group means of the residuals, $\mathrm{e}_{\mathrm{it}}$, are formed and denoted $\bar{e}_{i}$. These group means are used as dependent variables in an instrumental variable regression where $\mathbf{z}_{1}$ is used as instrumental variable for itself and $\mathbf{x}_{1}$ as instrument for $\mathbf{z}_{2}$. Identification requires that $K_{1} \geq$ $\mathrm{L}_{2}$. The residual variance in this regression is a consistent estimator of $\sigma^{* 2}=\sigma_{\alpha}^{2}+\sigma_{\varepsilon}^{2} / T$. Since we now can derive an estimator of $\sigma_{\alpha}^{2}$, we can calculate the weight for feasible GLS by forming the estimate of

$\theta=\sqrt{\frac{\sigma_{\varepsilon}^{2}}{\sigma_{\varepsilon}^{2}+T \sigma_{\alpha}^{2}}}$.

The final step is a weighted instrumental variable estimation. The instrument set consists of deviations from individual means of time-varying variables, individual means of exogenous time-varying variables and levels of exogenous time-invariant variables: $\left(\left(\mathbf{x}_{1 i t}-\overline{\mathbf{x}}_{1 i t}\right),\left(\mathbf{x}_{2 i t}-\overline{\mathbf{x}}_{2 i t}\right), \mathbf{z}_{1 i}, \overline{\mathbf{x}}_{1 i t}\right)$.

A challenge with Hausman-Taylor estimation is that one has to specify whether or not a specific variable is considered to be correlated or uncorrelated with the individual latent variable, $\alpha_{\mathrm{i}}$. We find it likely that $\alpha_{\mathrm{i}}$ manifests physician quality as perceived by patients. Hence, we find it plausible that the time varying variables Short, Gray, Many and Proplist ${ }^{*}$ Short are correlated with $\alpha_{\mathrm{i}}$. Additionally, we assume that the time invariant variable Proplist is endogenous since a physician with whom many patients would like to be listed, is likely to have a high value of the latent quality characteristics. Specialist 1 is considered to be 
endogenous since being a specialist in general medicine signals a concern for quality that is likely to be positively correlated with $\alpha_{\mathrm{i}}$. In order to avoid the weak instrument problem there should be sufficient correlation between a variable that is instrumented and the instrument. We find that both Proplist and Specialist1 are reasonably well correlated with the time varying exogenous variables.

The last column of Table 3 shows the results from the Hausman-Taylor estimation. From the Hausman test we see that the model is not rejected. The estimates of the time varying variables exhibit the same signs and level of statistical significance as in the fixed effects estimation, and the magnitudes of the estimated coefficients are quite similar. The effect of Proplist is statistically significant and negative: A one percent increase in Proplist is estimated to reduce the number of switches by 1.14 percent.

\section{Concluding remarks}

This study is concerned with three issues. First, we question whether the information patients have about physician quality when they choose a physician influences the probability of switching physicians. Second, we examine whether physicians with a shortage of patients experience more patient switching than others and third, we test whether a physician with unfavorable characteristics as perceived by patients, can prevent patient switching by providing a higher quantity of services to his or her patients.

The results of the empirical studies are mainly in accordance with our theory. A physician with many people having him or her as the first choice when the list system was established, experiences less patient switching than less popular physicians. People who were allocated to their preferred GP had experience with the practice style, and ranked this GP first because they trusted him or her and felt confident about the way their health problems were handled (Kalda et al. 2003, Hjortdahl and Lærum 1992). On the other hand, people who did not get their preferred GP, were less informed about their assigned GP's medical quality, and hence, more likely to be disappointed and switch to another physician. Hence, we show that information on physician quality influences the volume of patients switching physicians.

We also find that GPs who experience a shortage of patients experience more patient switching than GPs with enough patients. This is both in accordance with theory and with 
results from our previous nationwide survey where we found that patient shortage is related to patient dissatisfaction (Lurås 2007). Dissatisfaction results in 'exit' in terms of switching, i.e. patients reveal their preferences by switching GPs. Physicians who experience patient shortage seem to have some characteristics related to personality or practice style that the population in general does not like. Hence, experiencing patient shortage is not only a matter of technical allocation of patients to GPs, but also signals characteristics of a GP.

From theory we predicted that physicians with a shortage of patients would compensate for unfavorable characteristics by providing more services, such as longer and more frequent consultations, to their patients. Our third result is that a higher level of service provision only has a very small impact on the number of patients who decide to switch, i.e. more services do not compensate for characteristics of physicians that patients dislike. Hence, it seems that benefits are less than costs at the margin, and the extra service provision the constrained GPs offer may be socially inefficient.

Harris (2003) surveyed a random sample of individuals between the ages of 21 and 64 with employer-related health benefits, drawn from a nationally representative panel of households. She concludes that despite predictions of the increasing importance of consumer choice in shaping the health care delivery system, patients are passive health care consumers of physician services (see also Salisbury, 1989). In contrast, our results imply that both people's choice of a physician and the decision to stay with a GP or switch to another, are thoroughly considered and related to the perceived quality of a GP. This finding finds support in the medical literature (see for instance Gandhi et al. 1997 and Wolinsky et al. 1982).

In Norway a GP's actual number and maximum number of patients are both posted at the internet page of the NIA. A recommendation to a person who has only the publicly available information when he considers switching physicians would be to choose the physician with the smallest difference between maximum and actual list size. The problem is, of course, that a physician's maximum list size is a magnitude that is determined by the physician. If patients stopped switching to physicians with great deficits of patients, these physicians would reduce their preferred list size, and the advice would not be of much worth. A more viable suggestion would perhaps be to publish the number of switches a physician experiences during a defined period. This measure could have two virtues: Switching decisions would be better informed and physicians would be encouraged to invest in quality to prevent patients from switching. 
An additional virtue is perhaps that physicians would not be encouraged to provide wasteful services to prevent switching.

\section{References:}

Bjerrum L., Sorensen, A. S., 1992. Hvorfor skifter patienter læge? Ugeskrift for læger 154, $3587-3589$

Cameron, A. C., Trivedi, P. K., 2005. Microeconometrics: Methods and applications (Cambridge University Press, Cambridge).

Dixon, P., Gravelle, H., Carr-Hill, R., Posnett, J., 1997. Patient movements and patient choice. Report for National Health Service Executive, York Health Economics Consortium.

Gandhi, I.G., Parle, J.V., Greenfield, S. M., Gould, S., 1997. A qualitative investigation into why patients change their GPs. Family Practice 14, 49-57.

Gravelle, H., Masiero, G., 2000. Quality incentives in a regulated market with imperfect information and switching costs: capitation in general practice. Journal of Health Economics 19, 1067-1088.

Green, W. H., 2003. Econometric analysis (Prentice Hall, New Jersey).

Grytten, J., Sørensen, R., 2008. Busy physicians. Journal of Health Economics 27, 510-518.

Harris, K. M., 2003. How Do Patients Choose Physicians? Evidence from a National Survey of Enrollees in Employment-Related Health Plans. Health Services Research 38, 711-732.

Hausman, J. A., Taylor, W. E., 1981. Panel data and unobservable individual effects. Econometrica 49, 1377-1398. 
Hirschman, A. O., 1970. Exit, voice and loyalty (Harvard University Press, Cambridge, Massachusetts).

Hjortdahl, P., Lærum, E., 1992. Continuity of care in general practice: effect on patient satisfaction. British Medical Journal 304, 1287-90.

Iversen, T., 2005. A study of income-motivated behavior among general practitioners in the Norwegian list patient system. HERO Working Paper 2005:8 (Health Economics Research Programme at University of Oslo, Oslo).

Iversen, T., Lurås, H., 2000. Economic motives and professional norms: The case of general medical practice. Journal of Economic Behavior and Organization 43, 447-471.

Kalda, R., Polluste, K., Lember, M., 2003. Patient satisfaction with care is associated with personal choice of physician. Health Policy 64, 55-62.

Klemperer, P., 1995. Competition when consumers have switching costs: An overview with applications to industrial organization, macroeconomics, and international trade. The Review of Economic Studies 62, 515-539.

Lurås, H., 2007. The association between patient shortage and patient satisfaction with general practitioners. Scandinavian Journal of Primary Health Care 25, 133-139.

McGuire, T. G., 2000. Physician agency. In A. J. Culyer and J. P. Newhouse: Handbook of Health Economics, Volume 1 (Elsevier Science, Amsterdam) 461-536.

Salisbury, C., 1989. How do people choose their doctor? British Medical Journal 299, 608610.

Wolinsky, F., Steiber, S., 1982. Salient issues in choosing a new doctor. Social Science and Medicine 16, 759-767. 


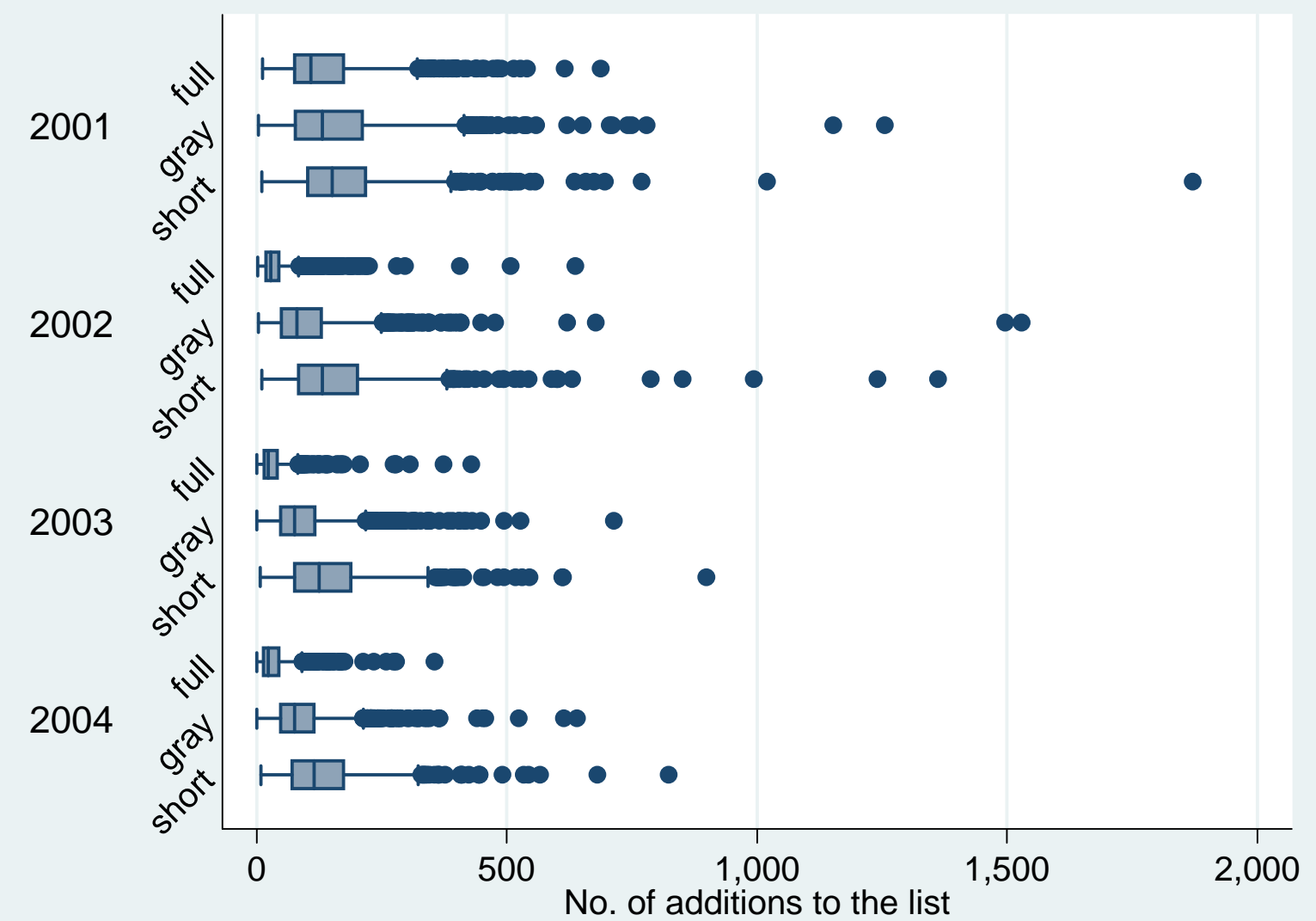

Figure A1. No. added to the list according to year and GP's list status (No. observations $=10,859$ ) 